\title{
Usefulness of Day 5 sampling in thyroid cancer patients for radioactive iodine therapy with recombinant human thyrotropin
}

Seo Young Sohn¹, Eun Kyung Lee², You Jin Lee², Yul Hwangbo², Hae Jin Jun²,Dae Yoon Park², Ji Hyun Kim² and Junsun Ryu²

1Department of Endocrinology and Metabolism, Seonam University, Myongji Hospital, Goyang, Korea.

${ }^{2}$ Center for Thyroid Cancer, National Cancer Center, Goyang, Gyeonggi, Korea

\section{Backgrounds}

We evaluated the impact of several anthropometric parameters on serum peak TSH levels after standard two-dose of recombinant human thyrotropin(rhTSH) injection and assessed the usefulness of repeated measurement of TSH and thyroglobulin ( $\mathrm{Tg}$ ) levels at 24 and $72 \mathrm{hrs}$ after rhTSH injection (Day 3 and 5) to confirm stimulated Tg level.

\section{METHODS}

We retrospectively reviewed 270 differentiated thyroid carcinoma patients who underwent rhTSH stimulation for radioactive iodine therapy in our clinic between 2013 and 2014. Serum TSH and Tg level were measured twice Day 3 and 5 after rhTSH injection. Univariate and multivariate analyses were performed to elucidate predictive factors of the peak TSH level. The repetitive values of $\mathrm{Tg}$ was compared by two-tailed paired T-test.

\section{RESULTS}

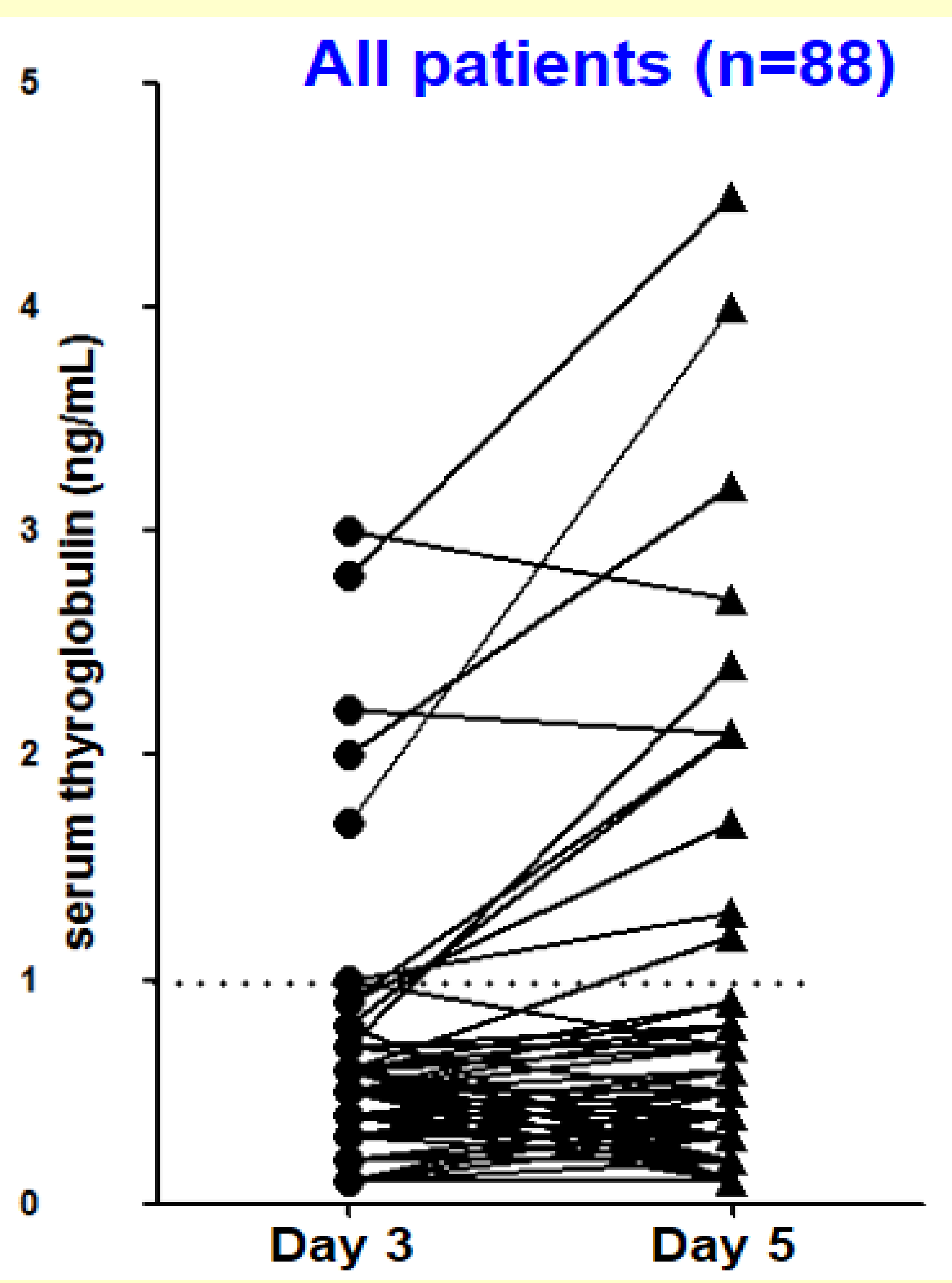

Figure 1. Comparison of Day 3 and Day 5 rhTSH-sTg

Table 1. Comparison of group according to sTg difference, Group $1 \geq 0.5$ vs. Group $2<0.5$

\begin{tabular}{l|c|c|c} 
& Group 1 $(\geq \mathbf{0 . 5 )}$ & Group 2(<0.5) & P-value \\
\hline Tumor size & $\mathbf{N = 8}$ & $\mathbf{N = 8 0}$ & \\
\hline T stage & & $1.1 \pm 0.7$ & NS \\
(T3-T4) & $7(87.5 \%)$ & $70(87.5 \%)$ & NS \\
Micro ET & $8(100 \%)$ & $70(87.5 \%)$ & NS \\
Gross ET & $3(37.5 \%)$ & $10(12.5 \%)$ & $\mathbf{0 . 0 6}$ \\
LN invasion & $6(75 \%)$ & $51(64 \%)$ & NS \\
N1a & $1(12.5 \%)$ & $41(51 \%)$ & \\
N1b & $5(62.5 \%)$ & $10(13 \%)$ & $\mathbf{0 . 0 2}$ \\
Multifocality & $2(25 \%)$ & $43(54 \%)$ & NS \\
Day3 sTg & $1.3 \pm 0.8$ & $0.5 \pm 0.4$ & $\mathbf{0 . 0 2}$
\end{tabular}

0.54 (day 3) vs 0.68 (day 5)

$\boldsymbol{P}=0.007$

sTg difference

$\geq 0.5 ; \mathrm{n}=8(9 \%)$

$\geq 0.5 ; \mathrm{n}=8(9 \%)$
$<0.5 ; \mathrm{n}=80(91 \%)$
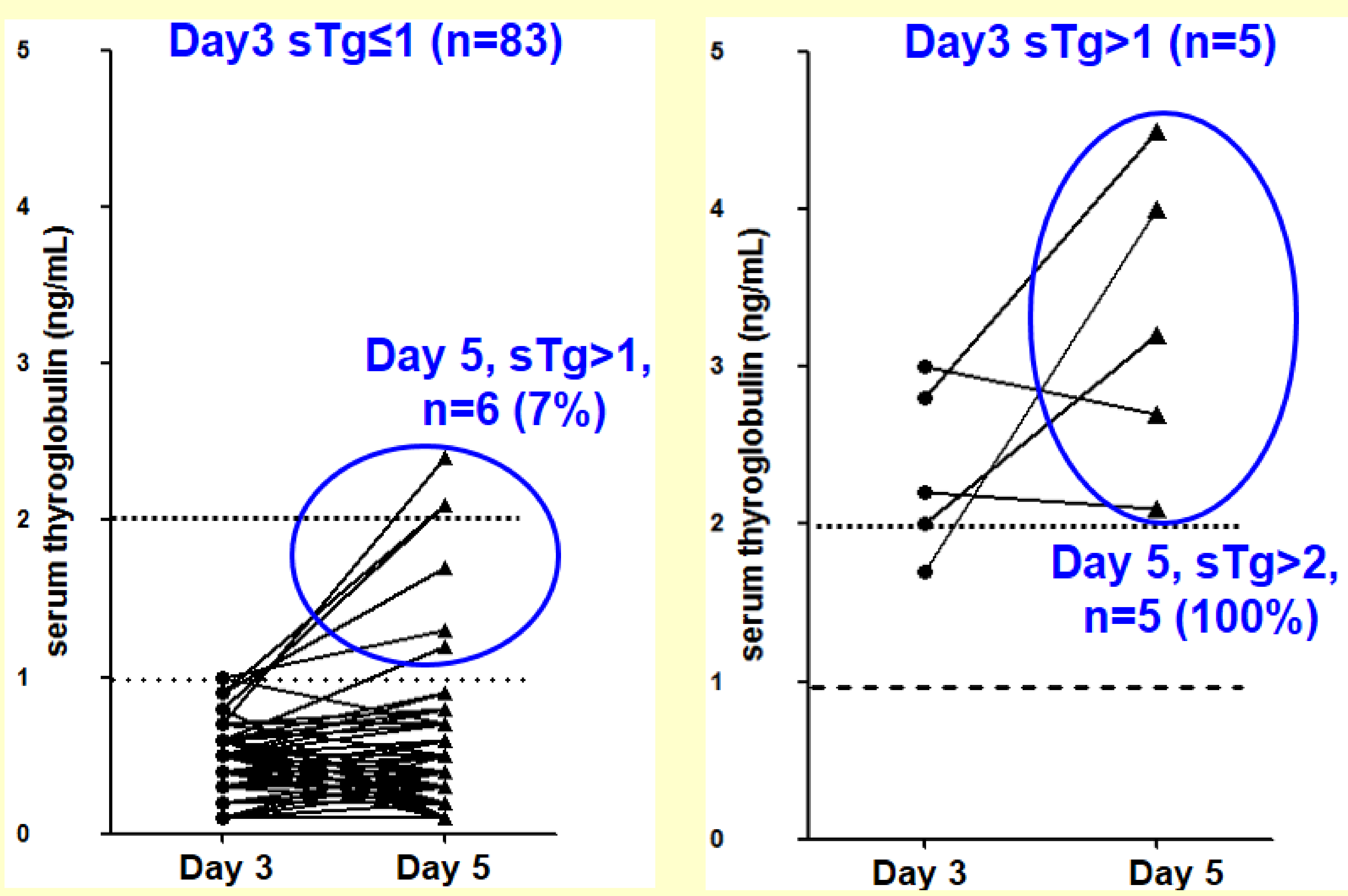

Figure 2. Comparison of Day 3 and Day 5 rhTSH-sTg based on Day3 sTg ( $\mathrm{sTg} \leq 1$ vs. $\mathrm{sTg}>1)$

Table 2. Multiple regression analysis

predictive factors of peak(day 3)TSH levels

\begin{tabular}{c|c|c|c|c|}
$\begin{array}{c}\text { Dependent } \\
\text { variable }\end{array}$ & $\begin{array}{c}\text { Independent } \\
\text { predictors }\end{array}$ & $\begin{array}{c}\text { Standardized } \boldsymbol{\beta} \\
\text { coefficient }\end{array}$ & $\mathbf{t}$ & p-value \\
\hline Peak TSH & BSA & -0.272 & -4.430 & $<0.001$ \\
& GFR & -0.324 & -5.287 & $<0.001$ \\
\hline
\end{tabular}

\section{CONCLUSIONS}

Body size and renal function influence serum peak TSH levels after rhTSH injection. On this basis, more personalized rhTSH dosage could be used in clinical practice, adjusted for BSA and GFR. The repeated measurement on Day 5 seemed to be necessary to assess stimulated Tg level.

\section{References}

1. Meier, C.A., et al., Diagnostic use of recombinant human thyrotropin in patients with thyroid carcinoma (phase I/II study). J Clin Endocrinol Metab, 1994. 78(1): p. 188-96.

2. Vitale, G., et al., Influence of body surface area on serum peak thyrotropin (TSH) levels after recombinant human TSH administration. J Clin Endocrinol Metab, 2003. 88(3): p. 1319-22.

Over, R, et al Age modifies the response to recombinant human thyrotropin. Thyroid, 2010. 20(12): $\mathrm{p}$. 1377-84.

4. Hautzel, H., et al., Impact of renal function and demographic/anthropomorphic variables on peak thyrotropin after recombinant human thyrotropin stimulation: a stepwise forward multiple-regression analysis. Thyroid, 2013. 23(6): p. 662-70. 